\title{
NUEVOS CONTEXTOS FUNERARIOS EN LA TRANSICIÓN PAMPEANO-PATAGÓNICA ORIENTAL (PCIA. DE BUENOS AIRES, ARGENTINA): APORTES AL HOLOCENO MEDIO Y TARDÍO INICIAL
}

\author{
NEW FUNERARY CONTEXTS IN THE EASTERN PAMPA-PATAGONIA \\ TRANSITION (BUENOS AIRES PROVINCE, ARGENTINA). CONTRIBUTIONS TO \\ THE MIDDLE AND INITIAL LATE HOLOCENE
}

Gustavo Martínez $z^{1}$ y Gustavo Flensborg ${ }^{1}$

\begin{abstract}
Este trabajo tiene como objetivo principal caracterizar el registro bioarqueológico y el contexto (estratigrafía y cronología) de cuatro nuevos sitios arqueológicos localizados en el área de transición pampeano-patagónica oriental adscritos al Holoceno Medio y Tardío inicial (ca. 6.000-1.000 años AP). Se propone evaluar y discutir las variaciones en las prácticas mortuorias y en el uso del espacio (costa-interior) por parte de grupos cazadores-recolectores. Se presentan los resultados de las modalidades de entierro, análisis cuantitativos, tafonómicos, y sexo-etarios. En los sitios localizados en el interior los restos están muy fragmentados y afectados por importantes factores tafonómicos (e.g., meteorización, abrasión sedimentaria), mientras que en el sector costero, la completitud anatómica es mayor, y los resultados tafonómicos indican estabilidad en la historia depositacional. La modalidad de entierro en los sitios costeros durante el Holoceno Medio habría sido primaria, en tanto ésta no pudo ser determinada en el interior. Por su parte, para el Holoceno Tardío inicial, mientras en la costa se registraron inhumaciones primarias, en el interior se observaron modalidades secundarias. La cronología obtenida indica la reocupación sistemática durante el Holoceno Medio y Tardío inicial tanto de los sectores costeros como interiores. Finalmente, los resultados se integran con la información cronológica obtenida sobre restos óseos humanos y las modalidades de entierro definidas para el sudeste Pampeano y Norpatagonia con el fin de discutir la contribución del caso de estudio a la bioarqueología de dichas regiones.
\end{abstract}

Palabras claves: Pampa-Patagonia, Holoceno Medio-Tardío inicial, cazadores-recolectores, prácticas mortuorias, tafonomía, costa-interior.

The purpose of this work is to characterize the bioarchaeological record and the contexts (stratigraphy and chronology) of recently recorded Middle and initial Late Holocene archaeological sites located in the eastern Pampa-Patagonia transition. The aims are to evaluate and discuss the variations in mortuary practices and in the use of space (coast-inland) by huntergatherers during ca. 6,000-1,000 years BP. Quantitative, taphonomic, sex and age-at-death as well as burial modalities data are presented. The obtained chronology indicates systematic reoccupation during the Middle and initial Late Holocene of coastal and inland sectors. While in inland sites human bone remains are highly fragmented and affected by important postdepositional factors (e.g., weathering, abrasion), in the coastal sector anatomical integrity is greater and taphonomy indicates stability in the depositional history. During the Middle Holocene, while burial modality at coastal sites would have been primary, it could not be determined in inland sectors. For the initial Late Holocene, while on the Atlantic coast primary burials were recorded, secondary modalities were detected in inland sectors. Finally, the results are integrated with the chronological information obtained on human skeletal remains and burial modalities defined for Southeastern Pampa and Northpatagonia in order to discuss the contribution of the case study presented here to the bioarchaeology of these regions.

Key words: Pampa-Patagonia; Middle and initial Late Holocene; hunter-gatherers; funerary practices; taphonomy coast-inland.

El estudio de restos humanos en el noreste de Patagonia y el sudeste de la región Pampeana (Argentina) se centró principalmente en contextos correspondientes al Holoceno Tardío (ca. 3.000350 años AP), ya que en este período se observa la mayor frecuencia de registro bioarqueológico (Bernal et al. 2008; Kaufmann y González 2013; Mariano 2011; Martínez et al. 2012a; Prates y Di Prado 2013; Scabuzzo et al. 2016; entre otros). Sin embargo, en estas regiones se localizaron también sitios con restos humanos cronológicamente vinculados al Holoceno Temprano y Medio (ca. 8.400-3.000 años

\footnotetext{
${ }^{1}$ INCUAPA-CONICET-UNICEN. Facultad de Ciencias Sociales, Universidad Nacional del Centro de la Provincia de Buenos Aires, Olavarría, Buenos Aires, Argentina.gmartine@ soc.unicen.edu.ar; gflensbo@ soc.unicen.edu.ar
} 
AP; Bonomo et al. 2013; Favier Dubois y Scartascini 2012; Flegenheimer et al. 2010; Politis et al. 2009; 2011; 2014; Scabuzzo y Politis 2011). Investigaciones sistemáticas en la transición pampeano-patagónica oriental, más precisamente en el curso inferior del río Colorado (Figura 1), han provisto detallada información bioarqueológica, principalmente para el Holoceno Tardío final (ca. 1.000-250 años AP). Se han recuperado varios entierros, la mayoría conformados por individuos inhumados bajo diversas modalidades (e.g., secundario múltiple y primario simple) y relacionados tanto con campamentos base como configurando áreas formales de entierro (Flensborg et al. 2017; Martínez 2010; Martínez et al. 2012a). Por el contrario, los contextos mortuorios del Holoceno Tardío inicial (ca. 3.000-1.000 años AP) son escasos, fragmentarios y se caracterizan por entierros primarios aislados asociados con campamentos base (Flensborg et al. 2017; Martínez et al. 2012a). Sin embargo, en los últimos años ha cobrado relevancia el hallazgo y estudio de nuevos contextos arqueológicos y colecciones de particulares localizados tanto en sectores del interior como en la costa, con cronologías correspondientes al Holoceno Medio y Tardío inicial (ca. 6.000-1.000 años AP), que han enriquecido el conocimiento bioarqueológico del área (e.g., paleopatología, prácticas mortuorias, cronología; Flensborg 2015; Flensborg et al. 2017; Martínez 2017; Martínez et al. 2012a, 2014).

Este trabajo tiene como objetivo principal caracterizar el registro bioarqueológico y contextual (e.g., estratigrafía y cronología) de nuevos sitios localizados en la transición pampeano-patagónica oriental para el Holoceno Medio y Tardío inicial (Figura 1). Se propone evaluar y discutir las variaciones en las prácticas mortuorias y en el uso del espacio (costa-interior) por parte de grupos cazadoresrecolectores, durante los ca. 6.000-1.000 años AP. Además se llevó a cabo un análisis de las historias tafonómicas de los sitios, del estado de preservación y de la representación de las unidades anatómicas en cada contexto, con el fin de comparar las tendencias obtenidas en distintos sectores del paisaje. Se presentan resultados sobre el número mínimo de individuos (NMI), sexo, edad de muerte y modalidad de entierro. Finalmente, los resultados obtenidos son integrados con la información disponible sobre restos humanos del sudeste de la región Pampeana y Norpatagonia a los efectos de evaluar la contribución del caso de estudio a la bioarqueología de dichas regiones.

\section{Características Generales del Área de Estudio y Estructura del Registro Bioarqueológico}

En este trabajo se analizan los restos humanos provenientes de cuatro sitios: Cantera de Rodados
Villalonga (CRV) y Tres Bonetes 1-colección Donnay (TB1), se ubican en inmediaciones de la costa Atlántica; mientras que La Modesta (LMO) y Loma de Los Morteros (LLM) se encuentran en el interior. Todos ellos se localizan en el partido de Patagones (provincia de Buenos Aires), al sur del río Colorado, en el interfluvio entre las cuencas inferiores del río Colorado y el río Negro (Figura 1). Esta área se emplaza en una zona ecotonal, de transición pampeano-patagónica (Martínez y Martínez 2017; Páez et al. 2001; Villamil y Scoffield 2003) y forma parte de la Diagonal Árida (Abraham de Vázquez et al. 2000).

Los sitios Tres Bonetes 1-colección Donnay (LS 40 11'25.3"; LO 62 21'46.8") y Cantera de Rodados Villalonga (LS 4006'59"; LO 62²0'50"), se localizan entre ca. 1,5-0,5 km de la costa Atlántica, en las adyacencias de la Bahía Anegada (Figura 1), compuesta por una serie de islas extendidas en sentido norte-sur y rodeadas por extensas llanuras de marea (Fucks et al. 2012). La línea de costa se caracteriza por depósitos litorales (albuferas, espigas, islas de barrera) y formas eólicas correspondientes al Pleistoceno Tardío-Holoceno (Fucks et al. 2012; Weiler 2000). Ambos sitios se localizan en actuales canteras de rodados, a unos ca. $10 \mathrm{~km}$ de distancia entre sí (Martínez et al. 2012b) (Figura 1). En el sitio Tres Bonetes 1, los restos humanos se hallaron en el límite de dos unidades estratigráficas (Figura 2A). La unidad superior se caracteriza por un sedimento de arena mediana a fina, de color castaño oscuro, con fragmentos de valvas de moluscos pequeños, restos de raíces y una importante cantidad de clastos de tamaño pequeño. En tanto, la unidad inferior está compuesta por sedimentos de arena mediana a gruesa, con estructura entrecruzada planar, laminar fina y abundantes valvas de moluscos y rodados (Figura 2B; ver una estratigrafía similar en Fucks et al. 2012; Martínez et al. 2012b; Weiler 2000). Estos depósitos corresponden a antiguos cordones litorales del episodio de transgresión postglacial, asociados con ambientes de islas de barreras y albuferas (Charó et al. 2013; Fucks et al. 2012; Weiler 2000). Los últimos episodios transgresivos corresponden al período del Holoceno Medio (ca. 6.500-3.500 años AP) (Weiler 2000).

Durante las actividades realizadas para la obtención de rodados con una pala mecánica se hallaron restos humanos que fueron recuperados por un operario y colocados en recipientes plásticos (baldes) y cajas (Figura 2C). El estudio de los esqueletos de ambos sitios fue realizado en su propiedad, en la localidad de Stroeder. En el caso de Tres Bonetes 1-colección Donnay, se visitó nuevamente el sitio y a través de tareas de prospección se localizaron restos óseos en la barranca situada en el sector occidental de la cantera. Este sector fue impactado por la maquinaria que removió parte 

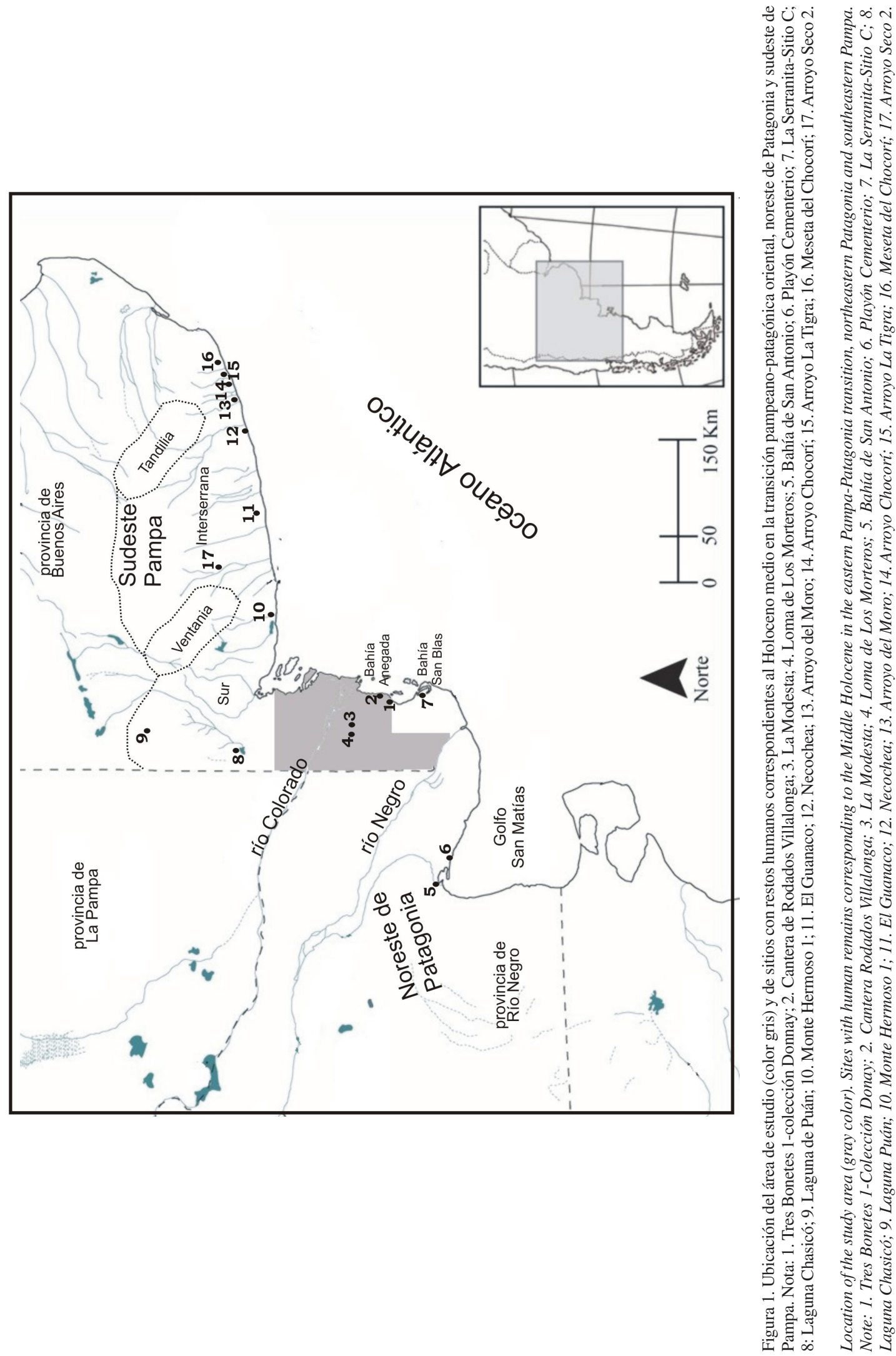
del sedimento que contenía el esqueleto. Se procedió a la excavación de una cuadrícula de 0,50 x 1,00 m, y a una profundidad de ca. $40 \mathrm{~cm}$ de la superficie del suelo actual se hallaron varios huesos articulados correspondientes a otro entierro (Figura 2D). Por el momento, ambos sitios son interpretados como sectores relacionados exclusivamente con áreas de entierros humanos (Martínez 2017; Martínez et al. 2012b), no habiéndose registrado hasta el momento evidencias de ocupaciones residenciales.

Los sitios Loma de Los Morteros (LS 39 42'55.9'; LO 62 48'58") y La Modesta (LS 39040'57.4"; LO $62^{\circ} 50$ '5.8”) se localizan muy cercanos entre sí (ca. $4 \mathrm{~km}$ ), a ca. $60 \mathrm{~km}$ de la costa atlántica (Figura 1) y presentan características similares. Éstos se encuentran en ambientes de dunas cercanos a antiguos paleocauces. Actividades antrópicas actuales a través del uso de palas mecánicas para la obtención de arena impactaron en las dunas que, sumado al accionar del viento, produjeron hoyadas de deflación en las cuales se registraron los materiales arqueológicos. Las actividades de campo realizadas incluyeron recolecciones superficiales sistemáticas a través de transectas, muestreos sub-superficiales y excavaciones sistemáticas (Carden y Martínez 2014; Martínez 2017; Stoessel 2015). Se observaron características estratigráficas similares en ambos sitios. Con la excepción de un depósito basal de origen fluvial registrado en La Modesta, el resto de las unidades estratigráficas están compuestas únicamente por sedimentos eólicos, donde predominan procesos agradacionales continuos y, en algunos casos, se registró la presencia de un horizonte A de suelo enterrado. Se hallaron escasos ítems enterrados, de tamaño muy pequeño, y no fue posible hallar un patrón de distribución estratigráfico que permitiera aislar componentes arqueológicos (Martínez 2017; Stoessel 2015). Por ende, la mayor parte del registro arqueológico estudiado proviene de los contextos superficiales. En ambos sitios se registraron restos óseos humanos, materiales de molienda, puntas de proyectil, preformas, desechos de talla, cáscaras de huevo de Rheidae grabadas, así como restos de fauna mayor (e.g., guanaco) y menor (e.g., peces, coipo), en algunos casos con evidencias de consumo (Alcaráz 2017; Carden y Martínez 2014; Martínez 2017). De las transectas se recolectaron fragmentos óseos humanos $\mathrm{y}$, aunque se registraron concentraciones de los mismos (Figura 3A), no fue posible reconocer alguna modalidad de inhumación. Trabajos posteriores en el sitio Loma de Los Morteros permitieron recuperar restos óseos humanos, algunos de ellos articulados, correspondientes a infantes (Figura 4A). El contexto y la información arqueológica indican que ambos sitios corresponden a asentamientos residenciales de actividades múltiples donde además se llevó a cabo el entierro de los individuos.

Se realizaron 11 fechados radiocarbónicos en 11 individuos diferentes (Tabla 1). Los resultados indican que en los sitios La Modesta y Cantera de Rodados Villalonga, los episodios de inhumación se ubican en el Holoceno Medio. En tanto, en los sitios Tres Bonetes 1-colección Donnay y Loma de Los Morteros, las dataciones indican diferentes momentos de entierro correspondientes al Holoceno Medio y Tardío inicial. Si se tienen en cuenta las dataciones calibradas (Calib Rev. 7.0.1; Reimer et al. 2013) se observa que, excepto por La Modesta, en el resto de los sitios se constataron diferencias temporales en las ocupaciones humanas (Tabla 1).

\section{Materiales y Métodos}

La muestra analizada corresponde a todos los restos humanos que se recuperaron en los cuatro sitios descritos (NMI = 12) (Tabla 2). A través de remontajes, varios fragmentos óseos pudieron ser asignados a un elemento específico, lo que permitió reconstruir las unidades anatómicas. En el caso de Tres Bonetes 1 y Cantera de Rodados Villalonga se realizaron análisis de correspondencia bilateral e intermembral (Todd y Frison 1992), a partir de criterios morfológicos, color, textura y estado de preservación del tejido óseo, lo que permitió asignar cada elemento a un individuo en particular (e.g., Martínez et al. 2012b:Figura 4).

Para el análisis cuantitativo se consideró el número de especimenes óseos (NISP), el número mínimo de elementos (NME) y el número mínimo de individuos (NMI) (Lyman 1994). También se aplicó el Î́ndice de Fragmentación (IF) teniendo en cuenta la relación NME/NISP, el cual varía entre 0 y 1 (Mondini 2003). El IF se dividió en tres categorías: alto $(0-0,3)$, moderado $(0,4-0,7)$ y bajo $(0,8-1)$. Por su parte, para estimar el grado de completitud de la unidad ósea, se calculó el porcentaje de hueso presente respecto de su totalidad. Se establecieron rangos porcentuales para describir la completitud del hueso: $1-25 \%, 26-50 \%$, 51-75\% y 76-100\% (González 2012).

Para la determinación del sexo se realizaron observaciones macroscópicas sobre diferentes rasgos cualitativos y/o morfológicos compilados en Buikstra y Ubelaker (1994). Se analizaron seis rasgos del cráneo que incluyen el desarrollo, tamaño y robusticidad de la protuberancia externa del occipital, senos frontales, glabela, procesos mastoideos, arcos supraorbitarios y la proyección de la eminencia mentoniana. En los coxales se tuvieron en cuenta los rasgos y las dimensiones de la escotadura ciática mayor, el arco y la morfología de la región subpúbica (concavidad subpúbica, superficie medial y arco ventral; Buikstra 


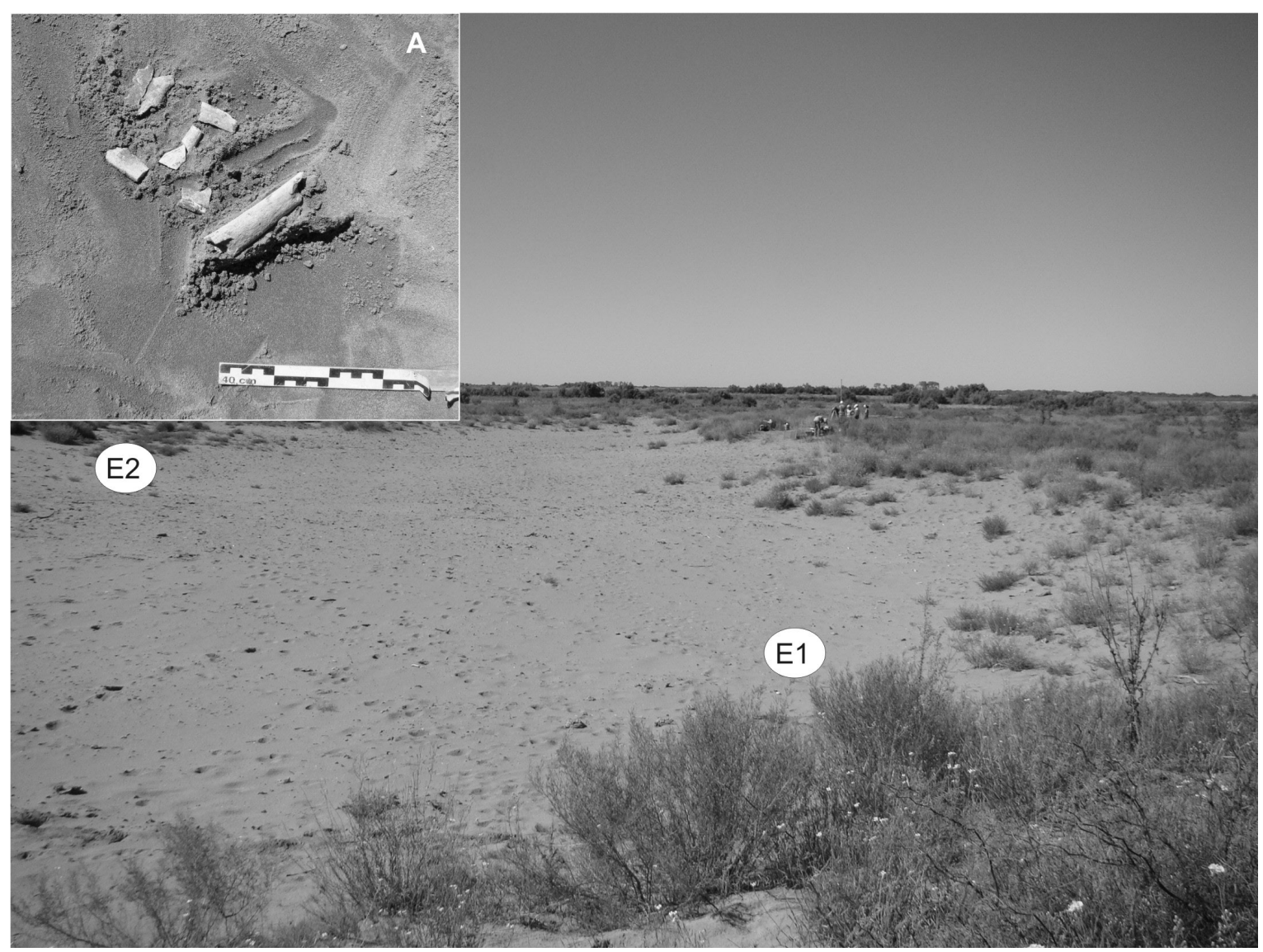

Figura 3. Sitio La Modesta. Localización de los dos individuos en la hoyada de deflación. (A) En el extremo superior izquierdo, restos óseos humanos dispersos de un adulto correspondientes al Entierro 2 (E2).

La Modesta site. Location of the two individuals in the blowout. (A) Upper left corner: scattered human skeletal remains of an adult corresponding to Burial 2 (E2).

Tabla 1. Fechados radiocarbónicos.

Radiocarbon dates.

\begin{tabular}{llllll}
\hline \multicolumn{1}{c}{ Sitio } & Código & Edad C14 AP & \multicolumn{1}{c}{ Edad cal. AP 2 $\sigma^{*}$} & SC13\%o \\
\hline Tres Bonetes 1-E1 & AA-106786 & $5.188 \pm 40$ & $5.749-5.992$ & $-13,3$ & Martínez 2017 \\
Tres Bonetes 1-E2 & AA-106787 & $5.182 \pm 46$ & $5.747-5.991$ & $-15,4$ & Martínez 2017 \\
Tres Bonetes 1-E3 & AA-106788 & $5.339 \pm 39$ & $5.941-6.201$ & $-13,1$ & Martínez 2017 \\
Tres Bonetes 1-E4 & AA-108187 & $1.868 \pm 26$ & $1.707-1.826$ & $-15,7$ & Martínez 2017 \\
Cantera de Rodados Villalonga-E1 & AA-91549 & $4.889 \pm 58$ & $5.330-5.710$ & $-15,1$ & Martínez et al. 2012b \\
Cantera de Rodados Villalonga-E2 & AA-91550 & $4.502 \pm 56$ & $4.874-5.288$ & $-13,4$ & Martínez et al. 2012b \\
Cantera de Rodados Villalonga-E3 & LP-2452 & $4.100 \pm 80$ & $4.297-4.825$ & -20 & Martínez et al. 2012b \\
La Modesta-E1 & AA-105416 & $5.890 \pm 52$ & $6.501-6.783$ & $-15,5$ & Carden y Martínez 2014; Stoessel 2015 \\
La Modesta-E2 & AA-107619 & $5.904 \pm 37$ & $6.559-6.783$ & $-19,0$ & Martínez 2017 \\
Loma de Los Morteros-E1 & AA-101876 & $4.454 \pm 60$ & $4.855-5.284$ & $-16,9$ & Carden y Martínez 2014; Stoessel 2015 \\
Loma de Los Morteros-E2 & AA-107620 & $1.114 \pm 25$ & $927-1.054$ & $-17,6$ & Martínez 2017 \\
\hline
\end{tabular}

*Curva de calibración del Hemisferio Sur (SHCal13; Hogg et al. 2013) 


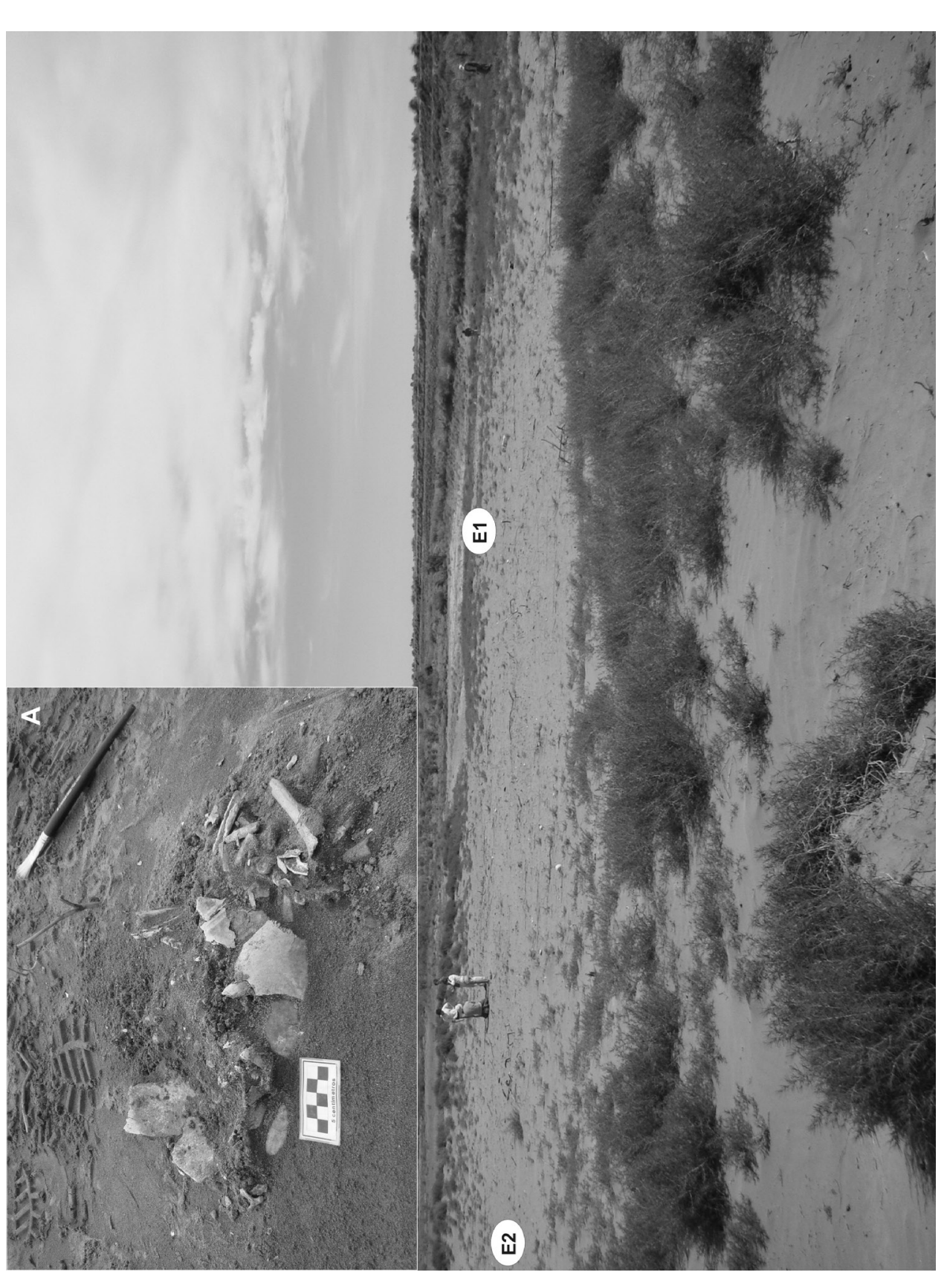

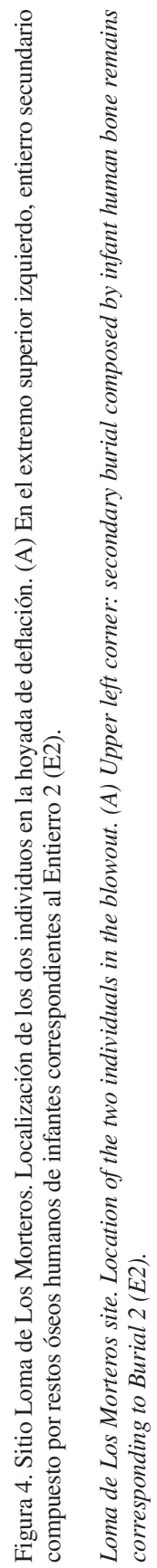


Tabla 2. Información sexo-etaria y cuantitativa por individuo. Nota: ( ) indica la cantidad de individuos en el entierro. Sex, age-at-death and quantitative information by individual. Note: ( ) indicates the number of individuals at the burial.

\begin{tabular}{|c|c|c|c|c|c|c|c|}
\hline Sitio & $\begin{array}{l}\text { Entierro/ } \\
\text { Individuo }\end{array}$ & Sexo & $\begin{array}{c}\text { Edad de } \\
\text { muerte (años) }\end{array}$ & NISP & NME & IF & $\begin{array}{l}\% \text { Completitud } \\
\text { anatómica }\end{array}$ \\
\hline \multirow{4}{*}{ TB1 } & 1 & masculino & $35-50$ & 98 & 70 & 0,7 & $76-100$ \\
\hline & 2 & femenino & adulto indet & 131 & 61 & 0,5 & $26-50$ \\
\hline & 3 & masculino & $35-50$ & 78 & 51 & 0,6 & $51-75$ \\
\hline & 4 & femenino & adulto indet & 95 & 28 & 0,3 & $76-100$ \\
\hline \multirow{3}{*}{ CRV } & 1 & masculino & $35-45$ & 49 & 40 & 0,8 & $51-75$ \\
\hline & 2 & masculino & $35-45$ & 37 & 20 & 0,5 & $51-75$ \\
\hline & 3 & femenino & $25-35$ & 53 & 27 & 0,5 & $26-50$ \\
\hline \multirow{2}{*}{ LMO } & 1 & indet & adulto indet & 28 & 14 & 0,5 & $1-25$ \\
\hline & 2 & indet & adulto indet & 125 & 9 & 0,07 & $1-25$ \\
\hline \multirow{2}{*}{ LLM } & 1 & indet & adulto indet & 88 & 12 & 0,1 & $1-25$ \\
\hline & 2 -Ind. 1 y $2-$ & indet (2) & $1,5-3(2)$ & 97 & 49 & 0,5 & $51-75$ \\
\hline Total & 12 & - & - & 879 & 381 & & - \\
\hline
\end{tabular}

y Ubelaker 1994). Para estimar la probable edad de muerte de individuos adultos se utilizaron coxales y se analizaron los cambios morfológicos presentes en la superficie auricular (Lovejoy et al. 1985; Meindl y Lovejoy 1989) y en la sínfisis púbica (Brooks y Suchey 1990). Para los subadultos, se consideró el estado y desarrollo de los centros de osificación (Scheuer y Black 2000), el estado de la fusión de las epífisis de los huesos largos y la secuencia de calcificación, formación y erupción de los dientes (Buikstra y Ubelaker 1994).

Con el propósito de estudiar los procesos y agentes tafonómicos que afectaron al conjunto de huesos se realizó un análisis macroscópico de los efectos resultantes en las superficies óseas. Para las marcas de raíces se relevaron los grabados dendríticos en la superficie cortical de los huesos (Lyman 1994), para las marcas de roedores se tuvo en cuenta la presencia de surcos de fondo plano, sin estrías en su interior y sección en "U" (Bocek 1986) y para las marcas de carnívoros las perforaciones, hoyos, bordes denticulados e incisiones (Binford 1981). En el caso del carbonato de calcio se consideró la presencia de una fina capa blanquecina pulverulenta, de pequeñas concreciones y/o de una cobertura dura y de variable espesor (Gutiérrez 2004), mientras que para el óxido de manganeso se registraron tinciones negras aisladas o agrupadas (Gutiérrez 2004). Para la abrasión sedimentaria se observó el pulido sobre el tejido cortical, la presencia de porosidad y el redondeo de los bordes de las unidades anatómicas (Lyman 1994). El deterioro químico se evaluó a partir de la presencia de líneas, estrías y grietas (Gutiérrez 2004). Por su parte, para la meteorización se consideraron los diversos estados del hueso (e.g., agrietamiento, escamado, astillamiento, exfoliación y fragmentación), incluyéndolos en alguno de los seis estadios propuestos (0-5; Behrensmeyer 1978).

\section{Resultados}

\section{Tres Bonetes 1-colección Donnay (TB1)}

En esta colección se cuantificó un número mínimo de 210 elementos óseos que representan a cuatro individuos adultos de ambos sexos (Tabla 2). Los tres primeros individuos fueron recolectados por el operario de la máquina y están presentes los huesos de distintos sectores del esqueleto, principalmente cráneo, miembros inferiores y superiores, cinturas pélvicas y escapulares, costillas y vértebras, mientras que los huesos de las manos y los pies son los menos representados (Figura 5). En estos casos no se pudieron determinar por observación directa las modalidades de inhumación. En el Individuo 4, el único excavado con metodología arqueológica, se observaron elementos óseos articulados, pertenecientes a la porción inferior de la columna vertebral (últimas dorsales y lumbares), costillas, cintura pélvica y miembros inferiores (Figuras 2D y 5). De acuerdo con la distribución y orientación de las unidades anatómicas se trata de una modalidad primaria, decúbito lateral izquierdo con los miembros inferiores flexionados.

El estado de preservación de los huesos es variable. Los Individuos 1 y 4 presentan los porcentajes de completitud ósea más elevados (76-100\%; Tabla 2), seguido por el Individuo $3(51-75 \%)$ y 2 (26-50\%). En todos los casos se registraron pérdidas óseas y ausencia de importantes regiones anatómicas (e.g., epífisis de huesos largos, cuerpos vertebrales; Figura 5). En los Individuos 1,2 y 3 el IF fue moderado (promedio de $0,6)$, a diferencia del Individuo 4 que fue alto $(0,3)$. A excepción del Individuo 4, la variable tafonómica más representada es el carbonato de calcio, que precipitó en forma de lámina sobre la superficie cortical de los elementos óseos, principalmente en el Individuo $1(93 \%)$, seguido por el Individuo $2(72,5 \%)$ y el 


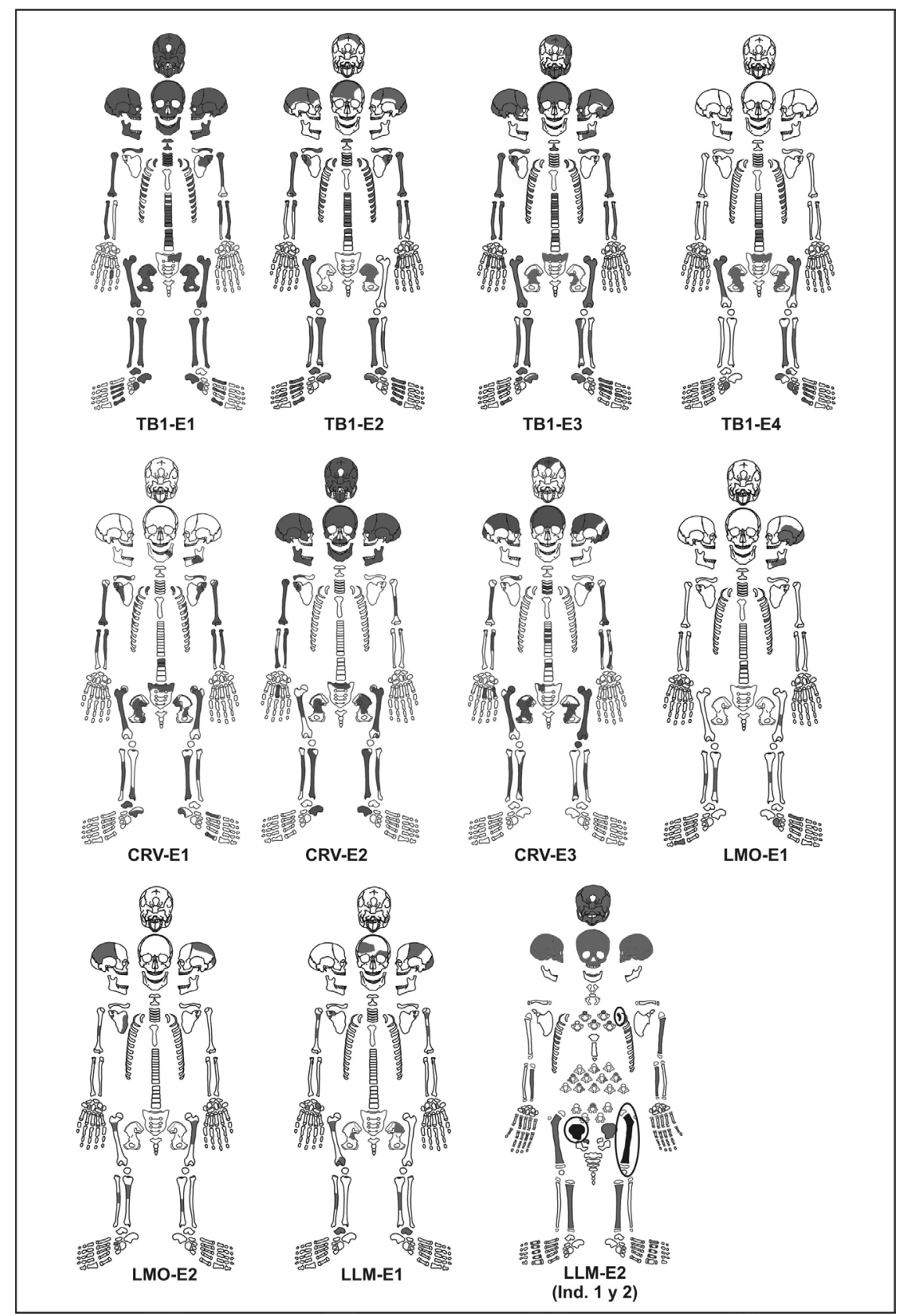

Figura 5. Representación de partes esqueletarias por individuo. Los esqueletos de Cantera de Rodados Villalonga (CRV) fueron tomados de Martínez et al. (2012b). Nota: TB1: Tres Bonetes 1; CRV: Cantera de Rodados Villalonga; LMO: La Modesta; LLM: Loma de Los Morteros; E: entierro. Nota: Los círculos en LLM-E2 indican los elementos que representan a los dos individuos identificados.

Skeletal part representation by individual. The skeletons of Cantera de Rodados Villalonga (CRV) were taken from Martínez et al. (2012b). Note: TB1: Tres Bonetes 1; CRV: Cantera de Rodados Villalonga; LMO: La Modesta; LLM: Loma de Los Morteros; E: burial. Note: Circles in LLM-E2 indicate the elements that represent the two different individuals identified. 
Individuo 3 (68,3\%) (Figuras 6, 7A y 7B). Respecto de las marcas de raíces, el Individuo 4 es el que presenta el mayor porcentaje (ca. 70\%; Figuras 6 y 7C), seguido en menor frecuencia por los demás individuos (rango entre 35-60\%). En líneas generales se observa un patrón dendrítico que afectó tanto mecánica como químicamente (e.g., tenue corrosión) el tejido óseo. Se identificó una baja frecuencia de marcas de roedores $(10,8 \%)$, todas ellas en el Individuo 4 (peroné, tibia y metatarso izquierdos; Figura 6). Finalmente, no se registraron elementos óseos con marcas de carnívoros, señales de abrasión sedimentaria, deterioro químico ni evidencias de meteorización.

\section{Cantera de Rodados Villalonga (CRV)}

En esta colección se cuantificó un número mínimo de 87 elementos óseos, correspondientes a tres individuos adultos de ambos sexos (Tabla 2). Los tres individuos fueron recolectados por el operario de la máquina, por lo que no se pudieron observar directamente las modalidades de inhumación. Se determinaron huesos correspondientes al cráneo, miembros inferiores y superiores y cinturas pélvicas, mientras que los huesos restantes están ausentes (Figura 5). En todos los casos se registraron pérdidas óseas menores y ausencia de regiones anatómicas (e.g., epífisis de huesos largos). El IF es bajo en el Individuo $1(0,8)$ y moderado en los Individuos 2 y 3 $(0,5)$. El porcentaje de completitud ósea es moderado en los Individuos 1 y 2 (51-75\%) y bajo en el Individuo $3(26-50 \%)$ (Tabla 2).

Las variables tafonómicas más representadas son el carbonato de calcio y las marcas de raíces (Figura 6). Se observó una delgada capa de carbonato de calcio sobre la superficie cortical (Figura 7D), principalmente en el Individuo $1(82,1 \%)$, seguido por el Individuo $2(53,1 \%)$ y el Individuo $3(24,9 \%)$. Las marcas de raíces se registraron en similares porcentajes en los tres individuos (ca. 40-50\%; Figura 6), y presentaron un patrón dendrítico que afectó el tejido óseo de manera mecánica y química. El resto de las variables tafonómicas no fueron observadas en los elementos óseos.

\section{La Modesta (LMO)}

En este sitio se cuantificó un número mínimo de 23 elementos óseos, correspondientes a dos individuos adultos de sexo indeterminado (Tabla 2). A través de transectas se recuperaron 14 unidades anatómicas dispersas en la superficie de la hoyada de deflación que pertenecen a un mismo individuo (E1), mientras que en un muestreo sub-superficial cercano a la hoyada se recolectaron nueve elementos óseos correspondientes a otro individuo (E2) (Figura 3).
Las unidades anatómicas se encuentran representadas principalmente por diáfisis de huesos largos, fragmentos del neurocráneo y, en menor medida, huesos de la mano y del pie (Figura 5). En ambos casos, la completitud anatómica es baja (1-25\%) y el IF varia de moderado (Individuo 1) a alto (Individuo 2) (Tabla 2). Como se observa en la Figura 6, la abrasión sedimentaria es la variable más representada en los restos óseos (ca. 95-100\%). Se observa el pulido del tejido cortical, la porosidad y el redondeo de los bordes de fractura (Figuras 8A y 8B). Además se relevó deterioro químico, principalmente en el Individuo $1(88,6 \%)$, seguido por el Individuo 2 (24,9\%). Se registró una baja frecuencia de meteorización (ca. 13$25 \%$; estadio 1), que habría generado la exfoliación del tejido cortical en la mayoría de los huesos. Las marcas de raíces y la depositación de carbonato de calcio presentan frecuencias bajas (ca. 10-30\%), y afectaron principalmente al Individuo 1. La depositación de óxido de manganeso se manifestó solo en el Individuo 1 , en baja frecuencia $(7,2 \%)$. Las marcas de roedores se registraron en porcentajes bajos en el Individuo $1(11,5 \%)$ y moderados en el Individuo $2(50 \%)$ (Figuras 6 y 8C). En ninguno de los restos óseos se observó acción de carnívoros.

\section{Loma de Los Morteros (LLM)}

En este sitio se recuperó un número mínimo de 61 elementos óseos que representan a un adulto y dos infantes de sexo indeterminado (Tabla 2). Las unidades anatómicas que corresponden al individuo adulto se hallaron dispersas en la superficie de la hoyada de deflación, por lo que no se pudo determinar la modalidad de inhumación, y fueron recuperadas a través de un muestreo de recolección por transectas. Se cuantificaron escasos restos óseos representados principalmente por diáfisis de huesos largos, fragmentos de cráneo y, en menor medida, huesos de manos y pies (Figura 5). Se registró una baja completitud anatómica (1-25\%) y un elevado IF $(0,1)$ (Tabla 2). Los restos óseos se encuentran afectados principalmente por la abrasión sedimentaria $(72,1 \%)$ (Figura 6) con características muy similares a los huesos del sitio anterior. En baja frecuencia se registró deterioro químico $(21,9 \%)$, marcas de raíces (17\%), depositación de carbonato de calcio $(15,3 \%)$, marcas de roedores (15\%) y meteorización $(14 \%$; estadio 1) (Figura 6). En el caso de los individuos infantes, los restos óseos se hallaron concentrados, asomando en la superficie del suelo (Figura 4A), por lo que se procedió a una excavación sistemática. Se trata de un entierro conformado por diferentes unidades anatómicas (e.g., coxales, cráneo, huesos largos, falanges, vértebras, etc.) (Figura 5). El análisis cuantitativo indicó la presencia de dos individuos a 


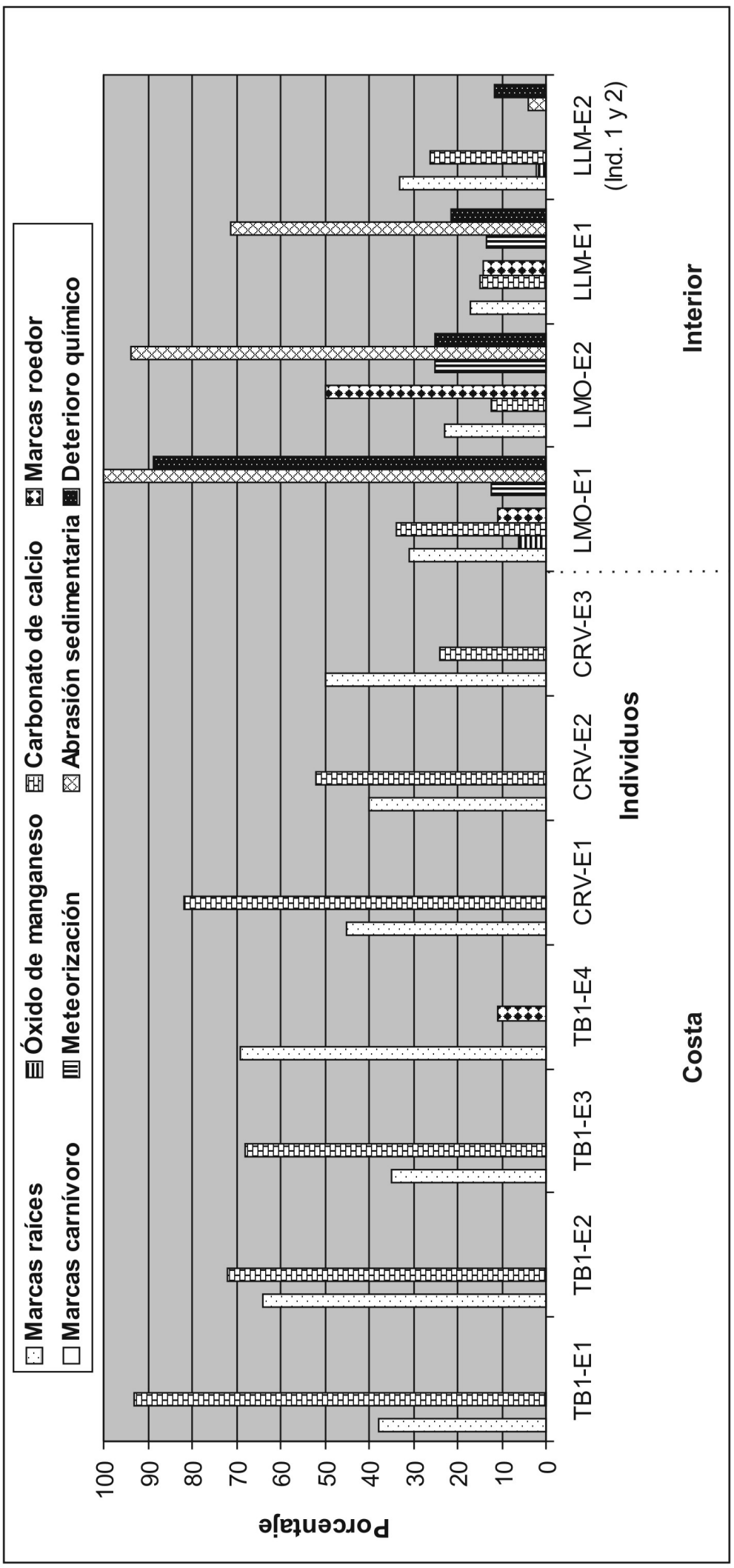

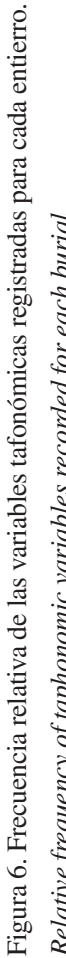



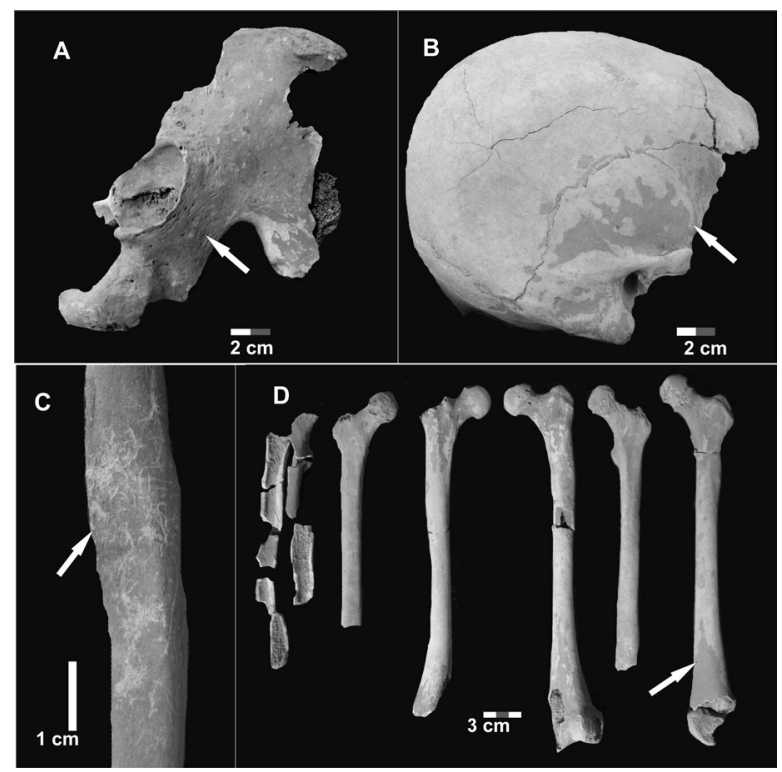

Figura 7. Estado de preservación ósea, completitud de las unidades anatómicas y efectos tafonómicos en huesos de sitios costeros. (A) Depositación de carbonato de calcio en toda la superficie cortical del coxal derecho de TB1-E1. (B) Depositación de carbonato de calcio y fracturas postmortem en el cráneo de TB1-E3. (C) Marcas de raíces en el radio derecho de TB1-E4. (D) Depositación de carbonato de calcio en los fémures de los tres individuos del sitio CRV. Pares de huesos homólogos que permitieron la discriminación de individuos.

Bone preservation, completeness of anatomical units and taphonomic effects of bones from coastal sites. (A) Calcium carbonate coating in the whole cortical surface of the right pelvic girdle of TB1-E1. (B) Calcium carbonate coating and postmortem fractures in the skull of TB1-E3. (C) Root etching in the right radius of TB1-E4. (D) Calcium carbonate coating in femurs of the three individuals of the CRV site. Pairs of homologous bones that allowed the identification of single individuals.

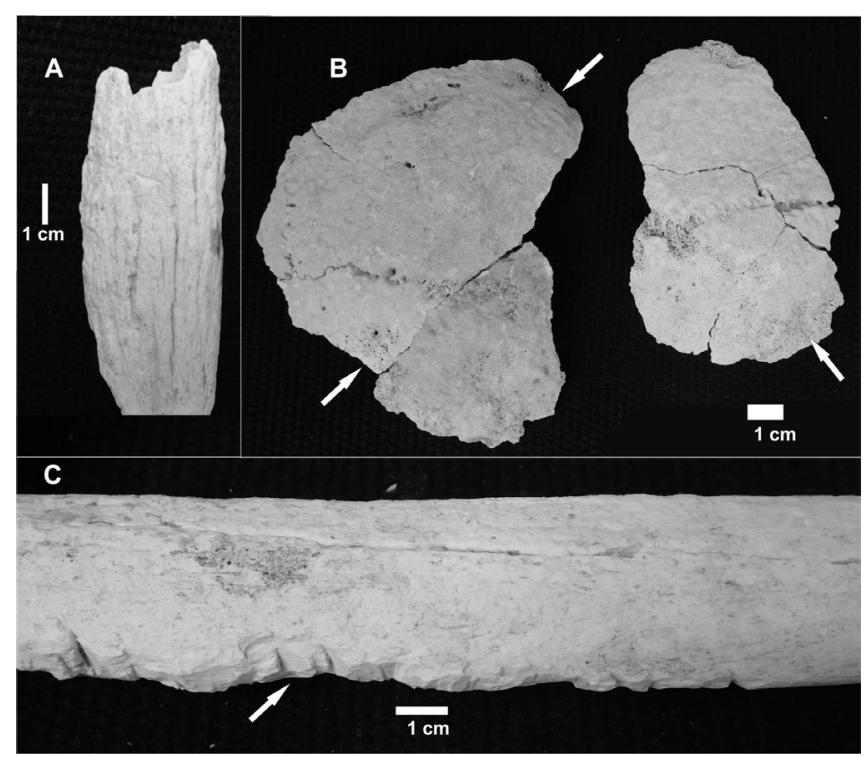

Figura 8. Estado de preservación ósea, completitud de las unidades anatómicas y efectos tafonómicos en huesos de sitios del interior. (A) Deterioro químico y abrasión sedimentaria en un fragmento de tibia derecha de LMO-E1. (B) Abrasión sedimentaria en dos fragmentos de cráneo de LMO-E1. (C) Abrasión sedimentaria, grietas de desecación y marcas de roedores en la diáfisis de la tibia derecha de LMO-E2.

Bone preservation, completeness of anatomical units and taphonomic effects of bones from inland sites. (A) Chemical deterioration and sedimentary abrasion in a fragment of the right tibia of LMO-E1. (B) Sedimentary abrasion in two skull fragments of LMO-E1. (C) Sedimentary abrasion, desiccation cracks and rodents marks on a diaphysis of the right tibia of LMO-E2. 
partir del pubis derecho, la primera costilla izquierda y el fémur izquierdo (Figura 5). En este sentido, se trata de una inhumación secundaria múltiple. Teniendo en cuenta que no se pudieron discriminar los huesos por individuo, se presentan los resultados de manera conjunta. El porcentaje de completitud anatómica es moderado (51-75\%), al igual que el Índice de Fragmentación $(0,5 \%)$. El análisis tafonómico indicó que las variables más representadas son las marcas de raíces $(33,2 \%)$, el carbonato de calcio $(26,7 \%)$ y el deterioro químico $(11,6 \%)$ (Figura 6).

\section{Discusión}

Los contextos funerarios descritos en este trabajo se encuentran perturbados por las condiciones accidentales de los hallazgos que, en algunos casos, llevaron a que los individuos fueran recuperados sin procedimientos metodológicos adecuados. A pesar de este escenario, dada la cronología de la mayoría de los entierros (Holoceno Medio), el registro bioarqueológico del área de estudio merece ser explorado ya que permite plantear algunas tendencias tanto a nivel areal como macrorregional.

Para la primera escala de análisis, los sitios localizados en cercanía de la costa atlántica (TB1 y $\mathrm{CRV}$ ) presentan un registro bioarqueológico similar. Se observó una escasa supervivencia de partes esqueletarias, pero el IF fue principalmente bajomoderado y con porcentajes de completitud anatómica más elevados que aquellos entierros localizados en los sitios del interior (LMO y LLM). Seguramente el bajo número de unidades anatómicas cuantificadas para TB1 y CRV (representado preferentemente por diáfisis de huesos largos, cráneos y coxales) se encuentre relacionado con el impacto que causó directa e indirectamente el uso de las maquinarias y a las condiciones de almacenamiento de los huesos. Además, en estos sitios la estrategia de recuperación de los esqueletos por parte del coleccionista implicó una recolección superficial sesgada a favor de los huesos más grandes y llamativos (e.g., cráneo, huesos largos), en detrimento de aquellos más pequeños (e.g., manos y pies). En cambio en TB1-E4, excavado por el equipo de investigación, solo se recuperaron las partes del esqueleto que permanecieron enterradas, mientras que los restantes huesos posiblemente fueron removidos por la pala mecánica, fragmentados y posteriormente cubiertos por la acumulación de sedimentos en la pendiente de la barranca. De acuerdo con los resultados tafonómicos se propone que los individuos de ambos sitios costeros fueron inhumados inmediatamente a su deceso, y permanecieron enterrados hasta el momento de su reciente recuperación, debido a la estabilidad del contexto geomorfológico. Esto se ve apoyado por la ausencia de meteorización, abrasión sedimentaria y marcas de carnívoros, indicando que los restos humanos no estuvieron expuestos a la superficie ni sujetos a la acción de factores atmosféricos. De acuerdo con la presencia de marcas de raíces se infiere que la vegetación fue uno de los agentes naturales que influyó, aunque levemente, en la preservación de los huesos, debido a que la superficie cortical sufrió daños mecánicos (e.g., fracturas) y en menor medida químicos (e.g., pequeñas lagunas de corrosión). El carbonato de calcio es la variable más representada (Figura 6). La génesis de esta depositación puede estar relacionada con la disolución química del sustrato de valvas localizado inmediatamente debajo de los entierros (Figura 2A), dado que constituye una importante fuente de $\mathrm{CaCO}_{3}$. Es probable que la ausencia de esta variable en el individuo TB1-E4 se deba a que fue enterrado varios centímetros por encima del límite entre las dos unidades estratigráficas descritas para el sitio, distante del sustrato de valvas. La ausencia de óxido de manganeso sugiere que los restos óseos humanos no estuvieron expuestos a condiciones microambientales de elevada humedad, que favorecieran el desarrollo de compuestos solubles de manganeso (Gutiérrez 2004).

Por su parte, en el caso de los sitios localizados en el interior (LMO y LLM), los escasos restos óseos humanos registrados en las hoyadas de deflación se encontraron muy fragmentados y en porcentajes bajos de completitud anatómica (Tabla 2). Esta característica probablemente se corresponda con el daño producido por las maquinarias y la exposición por tiempo prolongado a diversos agentes atmosféricos en la superficie del sitio. Las modificaciones tafonómicas observadas dan cuenta de la perturbación del contexto depositacional. Se sugiere que los restos óseos habrían estado sometidos a la alternancia de procesos de enterramiento y de re-exposición producto de la propia dinámica del médano (ver una situación similar para los conjuntos faunísticos en Alcaráz 2017; Stoessel 2015). La presencia de óxido de manganeso, carbonato de calcio y marcas de raíces indicarían que estos restos estuvieron enterrados. Sin embargo, la re-exposición habría sometido a los huesos a la acción prolongada de la abrasión sedimentaria y la meteorización. En cambio, en el entierro de infantes de LLM el bajo porcentaje de abrasión sedimentaria y deterioro químico indicarían una mayor estabilidad postdepositacional. Es posible que este entierro se haya expuesto en momentos muy cercanos a su descubrimiento y excavación.

Debido a que los restos son parte de colecciones (costa), o de contextos altamente perturbados por procesos de formación (interior) no fue posible registrar por observación directa la modalidad 
de entierro de los individuos correspondientes al Holoceno Medio. Sin embargo, en los sitios ubicados en la costa (TB1 y CRV), en base a la relativa completitud de los esqueletos y a las características macroscópicas de la superficie ósea (e.g., textura, color), la modalidad de inhumación habría sido primaria (Martínez et al. 2012b). Por su parte, en el interior, dadas las características ya mencionadas, no fue posible reconocer modalidades de inhumación. Sin embargo, para los entierros correspondientes al Holoceno Tardío inicial (TB1-E4 y LLM-E2), fue posible definir diferentes modos de entierros. En este sentido, el individuo TB1-E4 se caracteriza por el tipo primario simple. La posición decúbito lateral izquierdo con los miembros inferiores flexionados se asemeja a aquellos individuos adultos recuperados en otros sitios de la transición pampeano-patagónica oriental, como La Primavera y El Puma 2 (Flensborg et al. 2017), para el lapso del Holoceno Tardío inicial (ca. 3.000-1.000 años AP), por lo que no se observan variaciones para este período. En el caso de LLM se definió un entierro secundario múltiple (LLM-E2; Ind. 1 y 2) para los ca. 1.100 años AP. Al igual que en otros contextos del área de estudio que corresponden al Holoceno Tardío inicial es esperable hallar este tipo de modalidades de inhumación en campamentos base (e.g., Zoko Andi 1) (Flensborg et al. 2017; Martínez et al. 2014). Sin embargo, este caso es original porque es la primera vez que se encuentra un entierro constituido solo por partes esqueletarias correspondientes a la categoría de edad infante. Generalmente, los huesos de este cohorte etario se encuentran asociados o acompañando a adultos en los fardos funerarios (Flensborg et al. 2015; Martínez et al. 2012a). Esta característica permite ampliar aún más la diversidad de prácticas funerarias registradas para el área de estudio (Flensborg et al. 2017; Martínez et al. 2012a).

Desde una perspectiva contextual y cronológica, los individuos recuperados cerca de la costa atlántica fueron hallados en estratigrafía, por encima de un depósito de origen marino (Fucks et al. 2012; Weiler 2000). Los valores radiocarbónicos obtenidos en los restos humanos de estos sitios indican que este sector del paisaje estuvo disponible para los grupos cazadores-recolectores al menos desde los ca. 5.300 años AP. Esto sugiere que utilizaron con recurrencia geoformas marinas, muy cercanas a la costa atlántica, para la inhumación de sus ancestros. Por su parte, los sitios LMO y LLM se localizan en ambientes eólicos de dunas cercanos a antiguos paleocauces, los cuales han sido afectados por una intensa morfogénesis. A pesar de esto, se trata de los contextos bioarqueológicos más tempranos detectados para el área de estudio (ca. 5.900 años AP). La presencia de entierros humanos en sitios arqueológicos con funcionalidades domésticas es una característica recurrente del área durante el
Holoceno Tardío (ca. 3.000-250 años AP) (Martínez 2010). Este caso de estudio permite incrementar la profundidad temporal de este comportamiento hacia el Holoceno Medio.

De acuerdo con la información contextual disponible para el Holoceno Medio (Martínez 2017) se sugiere que los grupos cazadores-recolectores tenían un claro conocimiento del área y probablemente este período se correspondería a una etapa de ocupación efectiva del espacio, caracterizada por una estrategia de ocupación estable (sensu Borrero 1994-1995; ver discusión en Martínez 2017). Asimismo, la información cronológica obtenida desde los entierros humanos indica el uso recurrente de ciertos sectores del paisaje para la inhumación de los individuos en lapsos separados por cientos y/o miles de años. De acuerdo con esto, es posible considerar a los sitios (excepto La Modesta) como lugares persistentes (sensu Schlanger 1992), es decir puntos del paisaje elegidos intencionalmente para diferentes actividades y prácticas sociales que fueron repetidamente ocupados a través del tiempo.

Desde una perspectiva regional, este caso de estudio constituye un antecedente relevante para la bioarqueología del noreste de Patagonia y el sudeste de la región Pampeana, especialmente en lo que respecta a los contextos del Holoceno Medio. Particularmente, respecto del noreste de Patagonia se han informado escasos contextos con restos humanos para el Holoceno Medio, que no superan los ca. 4.800 años AP. Todos ellos están ubicados en cercanía de la costa atlántica. Para la costa norte del golfo San Matías (Figura 1) se registraron solo dos individuos en sitios arqueológicos (e.g., Bahía de San Antonio, ca. 4.800 años AP y Playón Cementerio, ca. 3.100 años AP; Favier Dubois et al. 2009; Favier Dubois y Scartascini 2012). En tanto, en las inmediaciones de Bahía San Blas se reportó un individuo (La Serranita, sitio C, ca. 4.100 años AP) (Sanguinetti de Bórmida et al. 1999) (Figura 1). En el sudeste de la región Pampeana se han registrado numerosos contextos correspondientes al Holoceno Temprano y Medio tanto en sectores costeros como del interior. Esto incluye a las áreas sur (e.g., Monte Hermoso 1, Laguna de Puán; ca. 7.8003.300 años AP) (Politis et al. 2009; Oliva et al. 1991), Ventania (Laguna Chasicó; ca. 3.900 años AP) (Catella 2014) e Interserrana (e.g., Arroyo La Tigra, Chocorí, Arroyo del Moro, Meseta del Chocorí, Necochea, Arroyo Seco 2, El Guanaco sitio 2; ca. 8.400-6.800 años AP) (Bonomo et al. 2013; Flegenheimer et al. 2010; Politis et al. 2014) (Figura 1). De acuerdo con esto, la transición pampeano-patagónica oriental aporta nuevos contextos bioarqueológicos para el Holoceno Medio que permiten complementar el esquema mortuorio del noreste de Patagonia y del sudeste de la región Pampeana. 
Respecto de la modalidad de entierro durante el Holoceno Medio, en el sudeste de Pampa se han documentado principalmente entierros primarios (Bonomo et al. 2013; Politis et al. 2011). El único sitio que presenta entierros primarios y secundarios simples y múltiples es Arroyo Seco 2 (Politis et al. 2014). Esta información no ha sido brindada para el caso del noreste de Patagonia (costa norte del golfo San Matías), debido a los contextos perturbados de donde provienen los restos humanos (Favier Dubois et al. 2009; Mariano 2011). De acuerdo a lo discutido anteriormente es muy probable que las inhumaciones registradas en la transición pampeano-patagónica oriental durante el Holoceno Medio se correspondan con el tipo primario.

Durante el Holoceno Tardío inicial en el sudeste de la región Pampeana se observa una mayor cantidad de sitios y un registro mortuorio más complejo a nivel regional. Para este período predominó la modalidad primaria en las áreas Interserrana, Ventania y Sur, entre ca. 3.000 y 1.500 años AP (Aldazabal et al. 2004; Bonomo et al. 2013; Madrid y Barrientos 2000; Politis y Madrid 2001; Politis y Bonomo 2011; Scabuzzo et al. 2016). Sin embargo, cabe destacar que en el área Interserrana se detectaron en forma conjunta modalidades primarias y secundarias (e.g., El Guanaco, Túmulo de Malacara; ca. 2.700- 2.500 años AP) (Mazzia et al. 2004; Politis et al. 2011). Para la costa norte del golfo San Matías entre ca. 3.000 y 1.300 años AP se observó preferentemente el tipo primario (García Guraieb et al. 2010; Mariano 2011), aunque un sitio se caracterizó por una inhumación secundaria múltiple compuesta por individuos adultos y subadultos (sitio Cima de Los Huesos) (Mariano 2011). Para el curso medio e inferior del río Negro, así como para la península San Blas y Laguna del Juncal, las modalidades reconocidas son primarias, simples y múltiples entre el ca. 3.200-1.200 años AP (Bernal et al. 2008; Gordón 2011; Prates y Di Prado 2013; Prates et al. 2010; Sanguinetti de Bórmida 1999). De este modo, si bien se han observado sitios con inhumaciones secundarias, los entierros primarios son los que predominan en diferentes áreas, al igual que lo que ocurre con la transición pampeano-patagónica oriental durante el Holoceno Tardío inicial (Flensborg et al. 2017). En el caso del entierro secundario del sitio Loma de Los Morteros, aunque se han registrado contextos más tempranos representados por esta modalidad a nivel areal y regional (e.g., Zoko Andi 1, Cima de Los Huesos, El Guanaco) (Mariano 2011; Martínez et al. 2014; Mazzia et al. 2004), lo novedoso del mismo reside en la conformación del entierro compuesto solo por huesos de infantes.

En otra escala de análisis los resultados presentados aquí son útiles para discutir la naturaleza de las ocupaciones del Holoceno Medio, un bloque temporal ampliamente discutido en cuanto a la presencia e intensidad de la ocupación humana tanto en escalas areales como regionales y macro-regionales (Barberena et al. 2017; Barrientos y Perez 2005; Durán y Mikkan 2009; García 2010; Martínez et al. 2015; Mazzanti et al. 2015; Neme y Gil 2009; Politis 2014; entre otros). En este sentido, la cronología de los contextos arqueológicos y bioarqueológicos de la transición pampeano-patagónica oriental permiten complementar la información generada en el noreste de Patagonia y sudeste de Pampa para el Holoceno Medio y reforzar la propuesta de una ocupación humana continua para este periodo (Bayón et al. 2010:125; Favier Dubois 2013:91; Martínez 2017:302; Martínez et al. 2015:105; Mazzanti et al. 2015:225; Politis 2014:455-456).

\section{Conclusiones}

En este trabajo se dieron a conocer las primeras tendencias respecto de la estructura del registro bioarqueológico del Holoceno Medio y se complementó el conocimiento sobre las prácticas mortuorias del Holoceno Tardío inicial en la transición pampeanopatagónica oriental. A pesar del registro fragmentario y espacialmente diferencial (e.g., costa e interior), se logró obtener un estado de la cuestión respecto de las historias tafonómicas involucradas en diferentes sectores del paisaje y de cómo influyeron diferentes procesos naturales y culturales en la preservación del registro. Asimismo, fue posible avanzar en algunos aspectos como la determinación del sexo y la edad, modalidades de inhumación y cuestiones referidas a los sistemas de asentamiento en relación con las prácticas mortuorias. En este sentido, mientras en la costa los entierros se encuentran en espacios utilizados solo para la inhumación, en el interior los mismos están relacionados con bases residenciales con claros componentes domésticos. Las modalidades de entierro para el Holoceno Medio habrían sido preferentemente primarias. Además, la presencia de un entierro secundario múltiple compuesto por infantes con una cronología del Holoceno Tardío inicial introdujo una nueva variante dentro del esquema mortuorio hasta ahora observado para el área de estudio.

Finalmente se destacalaimportanciade considerar y poner en valor a las colecciones particulares y al registro fragmentario de restos óseos humanos. En este caso, sobre la base de estos contextos se obtuvieron importantes datos bioarqueológicos, estratigráficos y cronológicos, especialmente para un período recientemente discutido en la transición pampeanopatagónico oriental como es el Holoceno Medio y que sin dudas tiene un alto impacto en la arqueología del sudeste de la región Pampeana y el noreste de Patagonia. 
Agradecimientos: Un especial agradecimiento a la familia Donnay quien informó sobre la presencia de restos óseos humanos en dos sitios y brindó la posibilidad de analizarlos. A la Dra. Stoessel por los valiosos comentarios realizados al manuscrito. A dos evaluadores anónimos que contribuyeron al trabajo de manera significativa con sus comentarios. Las investigaciones fueron subvencionadas por ANPCYT (PICT No 242) y National Geographic Society (Grant \#9756-15). Agradecemos al INCUAPA-CONICET (FACSOUNCPBA).

\section{Referencias Citadas}

Abraham de Vázquez, E., K. Garleff, H. Liebricht, A. Reigaráz, F. Schäbitz, F. Squeo, H. Stingl, H. Veit y C. Villagrán 2000. Geomorphology and paleoecology of the arid diagonal in Southern South America. Geodesy, Geomorphology and Soil Science. Sonderheft ZAG: 55-61.

Alcaráz, AP 2017. La fauna Menor de Sitios Arqueológicos del Curso Inferior del Río Colorado (Provincia de Buenos Aires): Aspectos Tafonómicos y Subsistencia de Cazadores-Recolectores durante el Holoceno Medio y Tardío. Tesis Doctoral inédita. Facultad de Ciencias Sociales, Universidad Nacional del Centro de la Provincia de Buenos Aires, Olavarría.

Aldazabal, V., N.E. Weiler y E. Eugenio 2004. Una perspectiva geoarqueológica para comprender la ocupación humana en la costa central de la provincia de Buenos Aires. Intersecciones en Antropología 5:29-38.

Barrientos, G. y S.I. Perez 2005. Was there a population replacement during the mid-Holocene in the southeastern Pampas of Argentina? Archaeological evidence and paleoecological basis. Quaternary International 132:95-105.

Barberena, R., C. Méndez y M.E. De Porras 2017. Zooming out from archaeological discontinuities: The meaning of midHolocene temporal troughs in South American deserts. Journal of Anthropological Archaeology 46:68-81.

Bayón, C.A., A. Pupio, R. Frontini, R. Vecchi y C. Scabuzzo 2010 Localidad arqueológica Paso Mayor: nuevos estudios 40 años después. Intersecciones en Antropología 11:115-128.

Behrensmeyer, A.K. 1978. Taphonomic and ecological information from bone weathering. Paleobiology 4 (2):150-162.

Bernal, V., P. González, S.I. Perez y H. Pucciarelli 2008. Entierros humanos del noreste de patagonia: nuevos fechados radiocarbónicos. Magallania 36 (2):125-134.

Binford, L.R. 1981. Bones. Ancient Men and Modern Myths. Academic Press, New York.

Bonomo, M., C. Scabuzzo y D.C. León 2013. Cronología y dieta en la costa atlántica pampeana, Argentina. Intersecciones en Antropología 14:123-136.

Brooks, S.T. y J.M. Suchey 1990. Skeletal age determinations based on the os pubis: A comparasion of the Acsádi-Nemeskéri and Suchey-Brooks Methods. Human Evolution 5:227-238.

Buikstra, J. y D. Ubelaker 1994. Standards for Data Collection from Human Skeletal Remains: Proceedings of a Seminar at the Field Museum of Natural History. Arkansas Archaeological Survey Research Series No. 44, Arkansas.

Carden, N. y G. Martínez 2014. Diseños fragmentados. Circulación social de imágenes sobre cáscaras de huevo de Rheidae en Pampa y Norpatagonia. Boletín del Museo Chileno de Arte Precolombino 19 (2):55-75

Catella, L. 2014. Movilidad y Utilización del Ambiente en Poblaciones Cazadoras-Recolectoras del Sur de la Región Pampeana: la Cuenca del Arroyo Chasicó como Caso de Estudio. Tesis Doctoral inédita. Facultad de Ciencias Naturales y Museo, Universidad Nacional de La Plata, La Plata.

Charó, M.P., S. Gordillo y E.E. Fucks 2013. Paleoecological significance of Late Quaternary molluscan faunas of the Bahia San Blas area, Argentina. Quaternary International 30:135-149.

Durán, V. y R. Mikkan 2009. Impacto del volcanismo holocénico sobre el poblamiento humano del sur de Mendoza (Argentina). Intersecciones en Antropología 10:295-310.

Favier Dubois, C.M. 2013. Hacia una cronología del uso del espacio en la costa norte del Golfo San Matías (Río Negro, Argentina): Sesgos geológicos e indicadores temporales. En Tendencias Teórico-Metodológicas y Casos de Estudio en la Arqueología de Patagonia, editado por F. Zangrando, R. Barberena, A. Gil, G. Neme, M. Giardina, L. Luna, C. Otaola, L. Paulides, L. Salgan y A. Tívoli, pp. 87-96. Museo de Historia Natural de San Rafael, Sociedad Argentina de Antropología. Instituto Nacional de Antropología y Pensamiento Latinoamericano y Secretaría de Cultura, Buenos Aires.

Favier Dubois, C.M., F. Borella y R. Tykot 2009. Explorando tendencias en el uso humano del espacio y los recursos en el litoral rionegrino durante el Holoceno medio y tardío. En Arqueología de Patagonia: Una Mirada desde el Último Confin, editado por M. Salemme, F. Santiago, M. Álvarez, E. Piana, M. Vázquez y E. Mansur, pp. 985-998. Editorial Utopías, Ushuaia.

Favier Dubois, C.M. y F. Scartascini 2012. Intensive fishery scenarios on the North Patagonian coast (Río Negro, Argentina) during the Mid-Holocene. Quaternary International 256 (1):62-70.

Flegenheimer, N., C. Bayón, C. Scabuzzo, N. Mazzia, R. Vecchi, C. Weitzel, R. Frontini y M. Colombo 2010. Early-Holocene human skeletal remains from the Argentinean pampas. Current Research in the Pleistocene 27:10-12.

Flensborg, G. 2015. Health and disease of hunter-gatherer groups from the eastern Pampa-Patagonia transition (Argentina) during the Late Holocene. Anthropological Science 124 (1):29-44.

Flensborg, G., G. Martínez y P. Bayala 2015. Mortality profiles of hunter-gatherer societies: A case study from the Eastern PampaPatagonia Transition (Argentina) during the Final Late Holocene. International Journal of Osteoarchaeology 25:816-826.

Flensborg, G. , G. Martínez y P. Bayala 2017. Prácticas funerarias. Modalidades de inhumación y manejo de los cuerpos. En Arqueología de Cazadores-Recolectores del Curso Inferior del 
Río Colorado (Provincia de Buenos Aires, Argentina). Aportes al Conocimiento de las Ocupaciones Humanas PampeanoPatagónicas, editado por G. Martínez, pp. 175-191. Serie Monográfica 6. INCUAPA-CONICET-UNICEN, Olavarría.

Fucks, E., M. Charó y F. Pisano 2012. Aspectos estratigráficos y geomorfológicos del sector oriental patagónico bonaerense. Revista de la Sociedad Geológica de España 25 (1-2):29-44.

García, A. 2010. Human occupation during the Mid-Holocene in Western Argentina. Current Anthropology 51 (3):415-416.

García Guraieb, S., C. Mariano y C. Favier Dubois 2010. El buque sur: un entierro primario múltiple de 2300 años en la costa del Golfo San Matías, Río Negro, Argentina. Magallania 38 (1):137-148.

González, M.E. 2012. Procesos de Formación en el Registro Bioarqueológico de la Sub-Región Pampa Húmeda y Área Ecotonal Pampa-Patagonia. Tesis Doctoral inédita, Facultad de Ciencias Sociales, Universidad Nacional del Centro de la Provincia de Buenos Aires, Olavarría.

Gordón, F. 2011. Dinámica Poblacional, Conflicto y Violencia en el Norte de Patagonia durante el Holoceno Tardio: Un Estudio Arqueológico. Tesis Doctoral inédita. Facultad de Ciencias Naturales y Museo, Universidad Nacional de La Plata, La Plata

Gutiérrez, M. 2004. Análisis Tafonómicos en el Área Interserrana (Provincia de Buenos Aires). Tesis Doctoral inédita, Facultad de Ciencias Naturales y Museo, Universidad Nacional de La Plata, La Plata.

Hogg, A.G., P.G. Blackwell, M. Niu, C.E. Buck, T.P. Guilderson, T.J. Heaton, J.G. Palmer, P.J. Reimer, R.W. Reimer, C.S.M Turney y S.R.H. Zimmerman 2013. SHCal13 Southern Hemisphere calibration, 0-50,000 years cal BP. Radiocarbon 55 (4):1889-1903.

Kaufmann, C.A. y M.E. González 2013. Rescate arqueológico de restos óseos humanos en el sitio Laguna Seca 1 (partido de General Lamadrid, provincia de Buenos Aires). Revista del Museo de La Plata. Sección Antropología 13 (87):1-12.

Lovejoy, C., R. Meindl, R. Mensforth y T. Barton 1985. Multifactorial determination of skeletal age at death: A method and blind tests of its accuracy. American Journal of Physical Anthropology 68:1-14.

Lyman, R.L. 1994. Vertebrate Taphonomy. Cambridge Manuals in Archaeology. Cambridge University Press, Cambridge.

Madrid, P. y G. Barrientos 2000. La estructura del registro arqueológico del sitio Laguna Tres Reyes 1 (Provincia de Buenos Aires): nuevos datos para la interpretación del poblamiento humano del Sudeste de la Región Pampeana a inicios del Holoceno Tardío. Relaciones de la Sociedad Argentina de Antropología XXV:179-206.

Mariano, C. 2011. Prácticas mortuorias y registro bioarqueológico en la costa rionegrina del golfo San Matías, Argentina. Intersecciones en Antropología 12:17-30.

Martínez, G. 2010. Entierros humanos en lugares sagrados y domésticos durante el Holoceno tardío: el registro bioarqueológico del curso inferior del río Colorado (provincia de Buenos Aires, Argentina). Werkén 13:145-161.

Martínez, G. 2017. Discusión. En Arqueología de CazadoresRecolectores del Curso Inferior del Río Colorado (Provincia de Buenos Aires, Argentina). Aportes al Conocimiento de las Ocupaciones Humanas Pampeano-Patagónicas, editado por G. Martínez, pp. 255-297. Serie Monográfica 6. INCUAPACONICET-UNICEN, Olavarría.

Martínez, G., G. Flensborg y P. Bayala 2012a. Human corpse manipulation and the body as symbol: A case study from the
Eastern Pampa-Patagonia transition (Argentina) during the Final Late Holocene. Journal of Anthropological Archaeology 31:215-226.

Martínez, G., G. Flensborg y P. Bayala 2012b. Primeras evidencias de restos óseos humanos en el curso inferior del río Colorado durante el Holoceno medio: sitio Cantera de Rodados Villalonga (pdo. de Patagones, pcia. de Buenos Aires). Cazadores Recolectores del Cono Sur. Revista de Arqueología 6:101-113.

Martínez, G.A. y G. Martínez 2017. Ambiente y geoarqueología. En Arqueología de Cazadores-Recolectores del Curso Inferior del Río Colorado (Provincia de Buenos Aires, Argentina). Aportes al Conocimiento de las Ocupaciones Humanas PampeanoPatagónicas, editado por G. Martínez, pp. 68-99. Serie Monográfica 6. INCUAPA-CONICET-UNICEN, Olavarría.

Martínez, G., G.A. Martínez, L. Stoessel, A.P.Alcaráz, F. Santos Valero, G. Flensborg, P. Bayala y J.F. Onorato 2014. Resultados preliminares del sitio arqueológico Zoko Andi 1 (transición pampeano-patagónica oriental). Revista del Museo de Antropología de Córdoba 7 (1):105-114.

Martínez, G., L. Prates, G. Flensborg, L. Stoessel, A.P. Alcaráz y P. Bayala 2015. Radiocarbon trends in the Pampean region (Argentina). Biases and demographic patterns during the final Late Pleistocene and Holocene. Quaternary International 356:89-110.

Mazzanti, D.L., G.A. Martínez y C.A. Quintana 2015. Asentamientos del Holoceno medio en Tandilia oriental. Aportes para el conocimiento de la dinámica poblacional de la región pampeana, Argentina. Relaciones de la Sociedad Argentina de Antropología XL (1):209-231.

Mazzia, N., C. Scabuzzo y R. Guichón 2004. Sobre cráneos, pelvis y otros huesos. Entierros humanos en el sitio El Guanaco. En Aproximaciones Arqueológicas Pampeanas. Teorías, Métodos y Casos de Aplicación Contemporáneos, editado por G. Martínez, M.A. Gutiérrez, R. Curtoni, M. Berón y P. Madrid, pp. 293-304. Facultad de Ciencias Sociales de Olavarría, Universidad Nacional del Centro de la Provincia de Buenos Aires, Olavarría.

Meindl, R. y C. Lovejoy 1989. Age changes in the pelvis: implications for paleodemography. En Age Markers in the Human Skeleton, editado por M. Isçan, pp. 137-168. Ch.C. Thomas Publisher, Springfield, Illinois.

Mondini, M. 2003. Formación del Registro Arqueofaunístico en Abrigos Rocosos de la Puna Argentina. Tafonomía de Carnívoros. Tesis Doctoral. Universidad de Buenos Aires, Buenos Aires.

Neme, G. y A. Gil 2009. Human occupation and increasing mid-Holocene aridity. Current Anthropology 50 (1):149-163.

Oliva, F., J. Moirano y M. Saghessi 1991. Estado de las investigaciones arqueológicas en el sitio Laguna de Puán 2. Boletín del Centro 2:127-138.

Páez, M.M., F. Schäbitz y S. Stutz. 2001. Modern pollen-vegetation and isopoll maps in southern Argentina. Journal of Biogeography 28:997-1021

Politis, G. 2014. Discusión y consideraciones finales. En Estado Actual de las Investigaciones en el Sitio Arqueológico Arroyo Seco 2 (Partido de Tres Arroyos, Provincia de Buenos Aires, Argentina), editado por G. Politis, M. Gutiérrez y C. Scabuzzo, pp. 439-459. Serie Monográfica 5. INCUAPA-CONICET-UNICEN, Olavarría, Argentina.

Politis, G., G. Barrientos y C. Scabuzzo 2014. Los entierros humanos de Arroyo Seco 2. En Estado Actual de las Investigaciones en el Sitio Arqueológico Arroyo Seco 2 (Partido de Tres Arroyos, Provincia de Buenos Aires, Argentina), editado por G. Politis, M. Gutiérrez y C. Scabuzzo, pp. 329-369. Serie Monográfica 5. INCUAPA-CONICET-UNICEN, Olavarría. 
Politis, G., G. Barrientos y T.W. Stafford 2011. Revisiting Ameguino: new ${ }^{14} \mathrm{C}$ dates from ancient human skeletons from the Argentine pampas. En Peuplements et Préhistoire en Amériques, editado por D. Vialou, pp. 43-53. Editions du Comité des travaux historiques et scientifiques, París.

Politis, G. y M. Bonomo 2011. Nuevos datos sobre el "Hombre Fósil" de Ameghino. En Vida y Obra de Florentino Ameghino, editado por J Fernicola, A. Prieto y D. Lazo, pp. 101-119. Publicación Especial 12, Asociación Paleontológica Argentina, Buenos Aires.

Politis, G. y P. Madrid 2001. Arqueología pampeana: Estado actual y perspectivas. En Historia Argentina Prehispánica, editado por E. Berberian y A. Nielsen, Tomo II, pp. 737-814. Editorial Brujas. Córdoba.

Politis, G., C. Scabuzzo y R.H. Tykot 2009. An approach to pre-Hispanic diets in the pampas during the Early/Middle Holocene. International Journal of Osteoarchaeology 19:266-280.

Prates, L. y V. Di Prado 2013. Sitios con entierros humanos y ocupaciones residenciales en la cuenca del río Negro (Norpatagonia, Argentina). Diacronía y multicausalidad. Latin American Antiquity 24 (4):541-466.

Prates, L., G. Flensborg y P. Bayala 2010. Caracterización de los entierros humanos del sitio Loma de los Muertos (valle medio del río Negro, Argentina). Magallania 38 (1):147-162.

Reimer, P.J., E. Bard, A. Bayliss, J.W. Beck, P.G. Blackwell, C. Bronk Ramsey, C.E. Buck, H. Cheng, R.L. Edwards, M Friedrich, P.M. Grootes, T.P. Guilderson, H. Haflidason, I Hajdas, C. Hatté, T.J. Heaton, D.L. Hoffmann, A.G. Hogg, K.A Hughen, K.F. Kaiser, B. Kromer, S.W. Manning, M. Niu, R.W Reimer, D.A. Richards, E.M. Scott, J.R. Southon, R.A. Staff, C.S.M. Turney y J. van der Plicht 2013. IntCal13 and Marine13 radiocarbon age calibration curves $0-50,000$ years cal BP Radiocarbon 55 (4):1869-1887.
Sanguinetti de Bórmida, A. 1999. Proyecto Nordpatagonia: Arqueología de la costa septentrional. Anales de la Academia Nacional de Ciencias 3-35.

Scabuzzo, C. y G. Politis 2011. Los entierros secundarios del Holoceno temprano y medio en la región pampeana. Nuevos datos del sitio Arroyo Seco 2. Cazadores Recolectores del Cono Sur Revista de Arqueología 4:135-155.

Scabuzzo, C., R. Frontini, R. Vecchi y C. Bayón 2016. Isótopos estables y dieta de los cazadores recolectores del sudoeste bonaerense (Argentina). Chungara Revista de Antropología Chilena 48 (3):383-395.

Scheuer, L. y S. Black 2000. Developmental Juvenile Osteology. Academic Press, London.

Schlanger, S. 1992. Recognizing Persistent Places in Anasazi Settlement Systems. En Space, Time and Archaeological Landscapes, editado por J. Rossignol y L. Wandsnider, pp. 91112. Plenum Press, Nueva York.

Stoessel, L. 2015. Tendencias preliminares sobre el consumo de peces durante el Holoceno medio en el área de transición pampeanopatagónica oriental (Pcia. de Buenos Aires). Archaeofauna. International Journal of Archaeozoology 24:103-117.

Todd, L. y G. Frison 1992. Reassembly of bison skeletons from the Horner Site: a study in anatomical reffiting. En Piecing Together the Past: Applications of Reffiting Studies in Archeology 578, editado por J. Hofman y J. Enloe, pp. 63-82. BAR International Series.

Villamil, C. y R. Scoffield 2003. Evaluación preliminar de la diversidad vegetal en el partido de Villarino (provincia de Buenos Aires). II Jornadas Interdisciplinarias del Sudoeste Bonaerense 3: 209-219.

Weiler, N. 2000. Evolución de los Depósitos Litorales en Bahía Anegada, Provincia de Buenos Aires, durante el Cuaternario Tardío. Tesis Doctoral inédita. Facultad de Ciencias Exactas y Naturales, Universidad de Buenos Aires, Buenos Aires. 